\title{
Thermodynamic and environmental consideration of advanced gas turbine cycles with reheat and recuperator
}

\author{
${ }^{1 *}$ B. Sheikhbeigi, ${ }^{2}$ M.B. Ghofrani \\ ${ }^{1}$ Department of Energy Engineering, Graduate School of the Environment and Energy, Science and Research Campus, \\ Islamic Azad University, Tehran, Iran \\ ${ }^{2}$ School of Mechanical Engineering, Sharif University of Technology,Tehran, Iran
}

Received 23 January 2007; revised 28 February 2007; accepted 10 March 2007; available online 20 March 2007

\begin{abstract}
The role of gas turbine power plants in electrical energy production has been considerably increased in the last two to three decades. Various methods have been proposed to improve the performance of gas turbine cycles. In this research, two methods, a reheat cycle (RC) and a cycle with a reheat and a recuperator (RHC), were investigated and compared with a simple cycle (SC). The main objective of this paper is to study the performance of an RC and RHC under actual conditions. In this regard, all processes are treated as actual, and in particular a relatively simple and reliable approach is used to predict the amount of cooling air. The results obtained on the basis of a model developed for this research show that reheating in the context of a realistic study may lead to an improvement both in efficiency and in specific net work using recuperator cause to decrease NOx emission.
\end{abstract}

Key words: Gas turbine, reheat, recuperator, advanced cycles

\section{INTRODUCTION}

The gas turbine cycle is a very flexible cycle so that its performance parameters, i.e. efficiency and specific net work, can be improved by adding extra components to a simple cycle. In recent years, much research has been carried out on advanced gas turbine cycles such as the steam injected gas turbine cycle (De Paepe, 2000), the humid air turbine (Stecco, 1993), the heat exchanger cycle (Facchini, 1993), etc. Generally, the main aim of these investigations has been to achieve a higher efficiency in gas turbine based cycles. A reheat combustion chamber is a component that can be added to a gas turbine cycle to improve its performance (Cohen, Rogers, 1993). In this method the expansion process in the turbine is divided into two processes and an additional combustion chamber is placed between the high-pressure and low pressure turbines. The exhaust gas from the high-pressure turbine (HPT), which contains sufficient oxygen, enters a reheat combustion chamber, and the temperature of the gases can be increased as a result of supplementary combustion. Previous research on the ideal reheat cycle (RC) shows that reheating increases specific net

\footnotetext{
*Corresponding author, Email: bsheikhbeigi@abanacds.com Tel.: +98912 320 3116; Fax: +9821 88842509
}

work but decreases efficiency compared with a simple cycle (SC). Also, these investigations show that the maximum specific net work in an RC is obtained if the pressure ratios for the high- and low-pressure turbines are assumed to be equal. Crane has shown that, although equal pressure ratios lead to a maximum specific net work, under this condition the efficiency is not maximum and the lower pressure ratio for the HPT increases the several investigations concerning reheating in gas turbines were carried out with some simplifications including: a constant specific heat, heat addition to the working fluid instead of to the combustion process and, more importantly, consideration of an uncooled turbine model (Crane, 1998) instead of a cooled turbine model. These assumptions, in particular the last one, lead to unrealistic results because almost all turbines today are usually cooled by air, and neglecting the amount of cooling air gives incorrect results. da Cunha Alves et al.investigated reheat and intercooling gas turbine cycles using a model that includes cooling air estimation. They concluded that an RC does not show a considerable efficiency change from an SC. It is worth noting that, in a cooled turbine model for an RC, the cooling air for the low-pressure turbine (LPT) does not 
actually need to have the pressure of the compressor outlet. It can be extracted from the intermediate stages of the compressor where the pressure is slightly higher than the LPT inlet pressure. If this way of cooling air extraction for the LPT is assumed, performance parameters of both the RC and the RHC can be improved for the following reasons:

1. The compressor input work can be reduced.

2. The cooling air temperature for the LPT is made lower.

As a result, the amount of cooling air for the LPT can be reduced.

In the present work an attempt is made to model an SC, RC and RHC considering all factors that actually affect the performance of real cycles. In this regard, specific heat was assumed to be a function of both temperature and combustion product composition, and the cooling air fraction was calculated using a relatively simple approach (Kreith, 1973). One of the distinguishing features of this investigation is that cooling air needed by the LPT has been extracted from intermediate stages of the compressor where the pressure is slightly higher than the LPT inlet pressure. In the interim, in this paper, in addition to an actual RC, an actual RHC was also analyzed and compared with the RC as well as with an SC.

\section{MATERIALS AND METHODS}

Thermodynamic analyses

General description

Fig. 1 illustrates the SC. In this cycle, cooling air is totally extracted from the compressor outlet. Fig. 2 presents the RC arrangement. After leaving the first combustion chamber, the hot gas enters the HPT where it expands partially. The gas, which contains sufficient unused oxygen, then enters the reheat combustion chamber where fuel is injected and supplementary firing occurs. The hot gas, now having a higher temperature (equal to the first turbine inlet temperature), enters the second, or low pressure, turbine where it expands to atmospheric pressure. In this cycle, cooling air for the HPT and LPT is extracted respectively from the compressor outlet and the compressor intermediate stage. Fig. 3 shows the RHC in which a heat exchanger is used to increase the air temperature before it enters the first combustion chamber by recovering heat from the LPT exhaust gases. The cooling air extraction points for this cycle are similar to those of the RC.
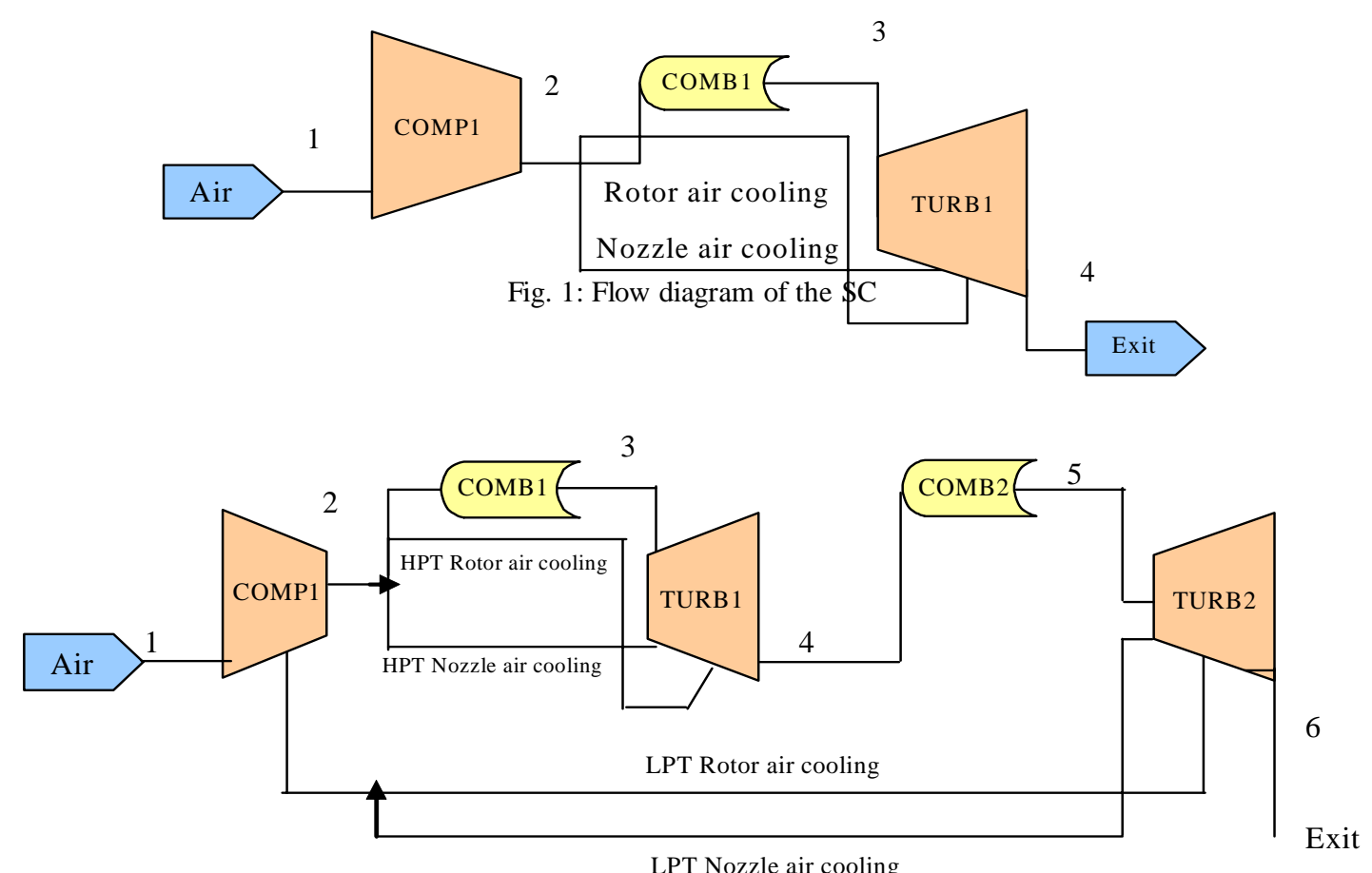

Fig. 2: Flow diagram of the reheat gas turbine cycle 


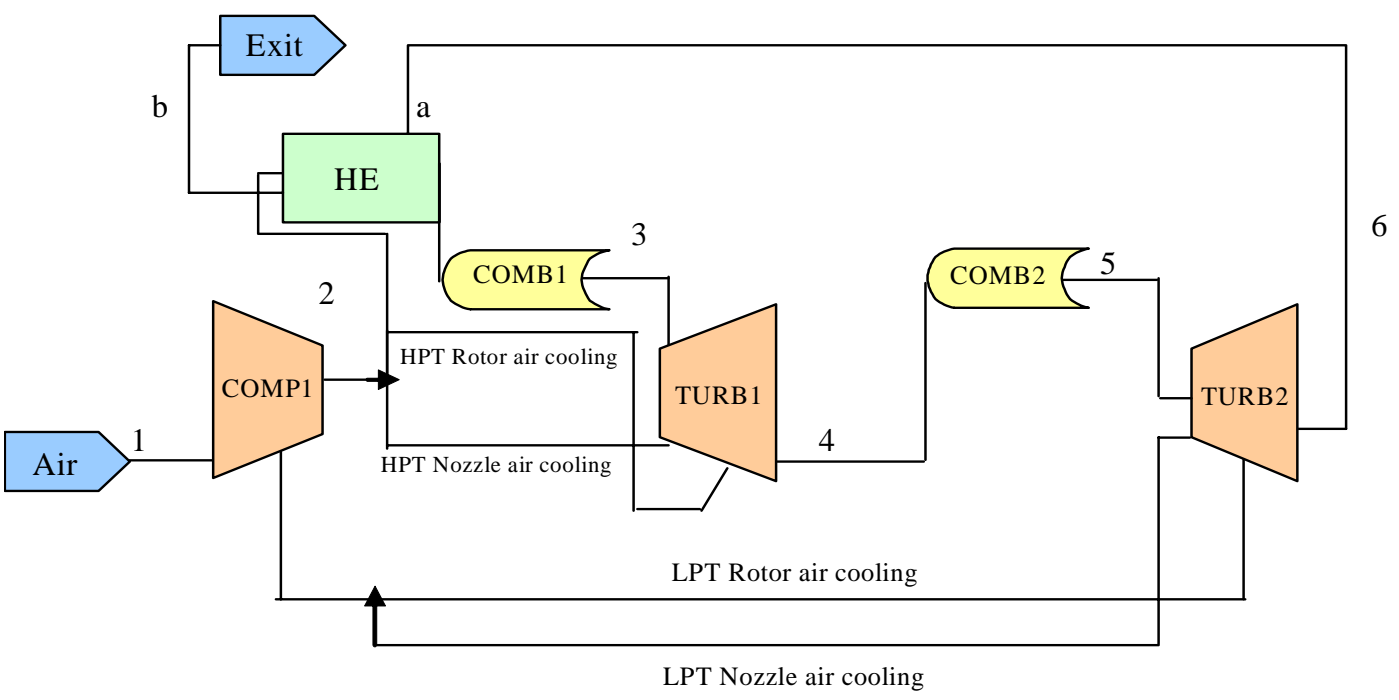

Fig. 3: Flow diagram of RHC

Compressor analysis

Using first law of thermodynamic and knowing exit temperature of compressor and the location of extraction for blade cooling, we can determine consumed work and isentropic efficiency. Here polytropic efficiency has been used to calculate exit condition. For one kilogram of inlet air to compressor, entropy change can be written as (El-Masri, 1986).

$d s=\bar{c}_{P M} \frac{d T}{T}-R \frac{d P}{P}$

Using the concept of polytropic efficiency, final exit temperature can be determined as:

$\bar{c}_{P M} \frac{d T}{T}=\frac{R}{\eta_{\infty c}} \frac{d P}{P}$

By integrating this equation, exit condition can be known, but compressor work consumption can not be determined till blade cooling air and its location is determined.

\section{Combustion chamber analysis}

The following chemical reaction can be written by assuming a general formula of $\mathrm{CnHm}$ for hydrocarbon fuel and a theoretical air coefficient A

$$
\begin{aligned}
& \mathrm{CnHm}+A\left(\frac{n+m}{4}\right)\left[\mathrm{O}_{2}+3.76 \mathrm{~N}_{2}\right] \Rightarrow(n) \mathrm{CO}_{2}+(m / 2) \mathrm{H}_{2} \mathrm{O} \\
& +\left[(A-1)\left(n+\frac{m}{4}\right)\right] \mathrm{O}_{2}+\left[3.76 \mathrm{~A}\left(\frac{n+m}{4}\right)\right] \mathrm{N}_{2}
\end{aligned}
$$

The first law of thermodynamics for an adiabatic combustion

$$
\sum_{i=1}^{n}\left(n_{i} h_{i}\right)_{\text {reac tan ts }}=\sum_{i=1}^{n}\left(n_{i} h_{i}\right)_{\text {ptoducts }}
$$

where

$h=h_{f}^{o}+\int_{298}^{T} C_{p}^{-} d T$

The theoretical air coefficient and then the fuel-air ratio can be calculated from equation (5) for any given turbine inlet temperature.

\section{Turbine analysis}

First, we consider non-cooled turbine, i.e. no coolant is extracted from the compressor. Similar to compressor, using polytropic efficiency of gas turbine, exit temperature can be determined. Inlet pressure of the turbine can be calculated by decreasing combustion chamber pressure drop from compressor discharge pressure:

$\int_{T_{4}}^{T_{3}} c_{P M} \cdot \frac{d T}{T}=\frac{R}{\eta_{\infty}} \cdot \int_{P_{3}}^{P_{4}} \frac{d P}{P}$

And produced work is:

$w_{\text {tur. }}=\frac{\left(1+f_{a c t}\right) \times \int_{T_{4}}^{T_{3}} \bar{c}_{P C . P .} d T}{M_{C . P .}}$ 
Cooled turbine model is based on El-Masri's work which has been modified and re-used by Bolland (GT PRO-GT MASTER, 2004) In this Model, blade temperature is an input (usually 1123K) and expansion path is considered to be continuous, instead of actual expansion (stage by stage expansion) (Sarabchi, 2000). Expansion path is divided into large number of substages with low pressure ratio. This model has been applied where parametric analysis of gas turbine is our goal and the knowledge of expansion path is not important. However, such a model can not deliver information about expansion path. For every sub-stage, mass of coolant can be determined as:

$\frac{m_{c}}{m_{g}}=\frac{C_{P . g}}{C_{P . c}} \cdot \sigma \cdot \frac{d T_{g}}{T_{a m b .}} \cdot \frac{\left(T_{g}-T_{b}\right)}{\left(T_{b}-T_{C}\right)}$

where ó is defined as:

$$
\sigma=\frac{S t \cdot \frac{A_{w, \text { stage }}}{A_{g}}}{C \cdot(k-1) \cdot M_{a}{ }^{2} \cdot \varepsilon}
$$

In the above equation, $m_{c}$ is the mass flow of coolant for sub-stage; $m_{g}$ is the mass flow of gas entering substage; $\mathrm{C}_{\mathrm{pg}}$ and $\mathrm{C}_{\mathrm{pc}}$ are the specific heat of gas and coolant respectively, $\mathrm{dT}_{\mathrm{g}}$ is the difference between inlet and outlet temperature; $\mathrm{T}_{\mathrm{b}}$ is the temperature of blade; $\mathrm{T}_{c}$ is the temperature of coolant entering blade. Parameter St is the Stanton number and is equal to 0.005 with good accuracy (Consonni, 1988). Ratio of $\left(\mathrm{A}_{\text {w,stage }} / \mathrm{A}_{\mathrm{g}}\right)$ for every stage is 10 and $\mathrm{C}$ is between 0.3 to 0.5. Non-dimensional parameter $\sigma$ is a critical parameter in gas turbine design with $\varepsilon$ having large influence on $\sigma$, its value changes depending on cooling technology. For convective cooling, its value is equal to 0.3 and for film cooling, equal to 0.5 . For hightechnology gas turbine, $\sigma$ is equal to $0.1-0.15$, while for others it is 0.4-0.45. Other turbine models such as stage by stage models have also been introduced to our model, but such a detailed model is not suitable for this case (Katsavou, 1995).

\section{Reheat combustion chamber analysis}

The equation of the combustion reaction for the reheat combustion chamber can be written as:

$$
\begin{aligned}
& x \mathrm{CnHm}+n \mathrm{CO}_{2}+\left(\frac{m}{2}\right) \mathrm{H}_{2} \mathrm{O}+(\mathrm{A}-1)\left(n+\frac{m}{4}\right) \mathrm{O}_{2}+3.76 \mathrm{~A}\left(n+\frac{m}{4}\right) N_{2} \Rightarrow \\
& (x+n) \mathrm{CO}_{2}+\left(2 x+\frac{m}{2}\right) N_{2}+\left[\left(n+\frac{m}{4}\right)(A-1)-2 x\right] \mathrm{O}_{2}
\end{aligned}
$$

Where $\mathrm{x}$ denotes the fuel consumed in the reheat combustion chamber per mole of fuel consumed in the primary combustion chamber. Parameter $\mathrm{x}$ and eventually the fuel-air ratio can be found by applying the energy balance equation to the reheat combustion chamber.

\section{Recuperator analysis}

In the heat exchanger the exhaust gas from the LPT is used to heat air before it enters the first combustion chamber, and therefore the fuel consumption is reduced in the combustion chamber. Recuperator effectiveness is defined by equation (11), considering the air to be a minimum fluid(Kreith, F. 1973):

$$
\varepsilon=\frac{q}{q^{\max }}=\frac{\int_{T_{2}}^{T_{a}} \bar{C}_{p a} d T}{\int_{T_{2}}^{T_{6}} \bar{C}_{p a} d T}
$$

Also, the energy balance for this component is:

$$
\int_{T_{2}}^{T} C_{p a}^{-} d T=\left(1+f_{1}+f_{2}\right) \int_{T_{b}}^{T_{6}} C_{p g 2}^{-} d T
$$

As T2 and T6 can be obtained respectively from the compressor and LPT models, it follows that the combustion chamber inlet temperature, Ta, and the heat exchanger exit temperature, $\mathrm{Tb}$, can be found from the above equations.

\section{RESULTS}

Point of introduction of reheat

A detailed investigation was made to find a suitable value of reheat pressure from the viewpoint of performance parameters (efficiency and specific net work). Fig. 5 shows the specific net work versus e for different values of the TITs and compressor pressure ratios. It should be noted that e is the exponent in the relation

$$
r_{h p t}=r_{c}^{e}, 0 \leq e \prec 1
$$

Also

$$
r_{h p t} r_{l p t}=r_{c}
$$

For e $=0 \quad r_{h p t}=1 \quad$ This refers to SC. 


$$
\begin{array}{ll}
\text { For e }=0.25 & r_{h p t}=r_{l p t}^{1 / 3} \\
\text { For e }=0.50 & r_{h p t}=r_{l p t} \\
\text { For e }=0.75 & r_{h p t}=r_{l p t}^{3}
\end{array}
$$

Examination of Fig. 5 shows that, for any TIT, the curves for different pressure ratios pass through a peak of wnet as the HPT pressure ratio is increased (or reheat pressure is decreased). It is also seen that the position of peak points does not depend on the TIT and only slightly depends on the compressor pressure ratio. In general, the peak points occur at $\mathrm{e}=0.4-0.5$, for which the HPT pressure ratio is almost equal to the LPT pressure ratio. It should be noted that the same result could also be obtained analytically for an ideal reheat cycle. Fig. 6 illustrates the thermal efficiency of the RC against e for various TITs and compressor pressure ratios. This diagram demonstrates that the curves pass a peak of efficiency as the HPT pressure ratio increases. The e values corresponding to peak points are in the range $0.2-0.3$ (for which $r_{\text {hpt }}=r^{1 / 3}$ lpt), and this is almost independent of the TIT and depends slightly on the pressure ratio. Another result is that the values of the peak efficiencies increase with increasing TIT and compressor pressure ratio. For instance, the peak efficiency for TIT $=1400{ }^{\circ} \mathrm{Cand} r_{c}=50$ is about $43.5 \%$ , whereas its value is about $33.5 \%$ for $\mathrm{TIT}=1000{ }^{\circ} \mathrm{C}$ and $=10$. Examination of Figs 5 and 6 show that the curves of specific net work for $\mathrm{e}=0.25-0.5$ are quite flat, but the variation in efficiency in the same range of e is considerable. Therefore, by designing the $\mathrm{RC}$ for maximum specific net work, the efficiency will be sacrificed notably and its value will even be lower than the SC efficiency. However, by designing the RC for maximum efficiency, the deviation in specific net work from its maximum value is not considerable. Hence, it can be concluded that the design the RC for maximum efficiency is much more appropriate than its design for maximum specific net work. This point will be investigated further in the following section.Figures 7 and 8 show the performance criteria of the RC based on various models. All models use the same assumptions outlined in section 2.9, the only difference between them being the issue of turbine air cooling. In the above figures, cooled model 1 for the RC refers to a model for which cooling air is extracted from both the intermediate stage and the compressor outlet and $\mathrm{e}=$ 0.5 . Model 2 is the same as model 1 except that $\mathrm{e}=0.25$ in model 3 the cooling air is totally extracted from the compressor outlet and $\mathrm{e}=0.5$. Examination of Fig. 7 illustrates that the uncooled model predicts very high values for specific net work compared with those obtained from the cooled models. Also, there is a considerable difference between the results of the various cooled models. The same difference is also seen for efficiency prediction based on various models (Fig. 8). An interesting point in this regard is that the value of efficiency predicted by cooled model 2 is higher than that predicted by an uncooled model. Therefore, accurate evaluation of the performance of RCs involves

\begin{tabular}{|c|c|c|c|c|c|c|c|}
\hline Gas turbine model & $\begin{array}{l}\text { PG } \\
5361\end{array}$ & $\begin{array}{l}\text { KWU } \\
94.2\end{array}$ & $\begin{array}{ll}\text { ABB } & \text { GT } \\
10 & \end{array}$ & $\begin{array}{l}\text { GE } \\
6541 B\end{array}$ & W501D5 & RB211 & GE9311FA \\
\hline Manufacturer & $\begin{array}{l}\text { General } \\
\text { Electric }\end{array}$ & Siemens & $\mathrm{ABB}$ & $\begin{array}{l}\text { General } \\
\text { Electric }\end{array}$ & Westinghouse & Rolls-Royce & $\begin{array}{l}\text { General } \\
\text { Electric }\end{array}$ \\
\hline Mass flow rate (kg/s) & 12.1 & 503 & 76.96 & 138 & 355.5 & 89.81 & 607 \\
\hline Pressure ratio & 10.56 & 10.9 & 13.96 & 11.8 & 14.17 & 20.02 & 14.6 \\
\hline Turbine inlet $\left(\mathrm{C}^{0}\right)$ & 985 & 1198 & 1218 & 1145 & 1180 & 1168 & 1348 \\
\hline $\begin{array}{l}\text { Power given by manufacturer } \\
\text { (MW) }\end{array}$ & 25.28 & 154 & 24.51 & 39.32 & 109.5 & 24.57 & 231.02 \\
\hline Power predicted by model (MW) & 26.04 & 155.9 & 24.23 & 39.65 & 104.87 & 23.8 & 230 \\
\hline Difference (\%) & +3 & +1.2 & -1.14 & +0.84 & -4.2 & -2.9 & -0.43 \\
\hline $\begin{array}{l}\text { Efficiency given by manufacturer } \\
(\%)\end{array}$ & 27.73 & 33.9 & 34.16 & 32.3 & 33.94 & 34.93 & 36.8 \\
\hline Efficiency given by model (\%) & 28.37 & 31.73 & 33.19 & 31.72 & 32.8 & 32.3 & 34.79 \\
\hline Difference (\%) & +2.3 & -6.4 & -2.83 & -1.79 & -3.3 & -2.8 & -5.77 \\
\hline $\begin{array}{l}\text { Exhaust gas temperature predicted } \\
\text { by manufacturer (\%) }\end{array}$ & 493 & 546 & 534 & 536 & 527.7 & 468 & 587 \\
\hline $\begin{array}{l}\text { Exhaust gas temperature predicted } \\
\text { by model (\%) }\end{array}$ & 483 & 588 & 558 & 548 & 535 & 480 & 613 \\
\hline Difference (\%) & -2.03 & +7.7 & +4.49 & +2.23 & +1.4 & +2.6 & +4.43 \\
\hline
\end{tabular}
using a suitable model for this purpose.

Table 1 Performance prediction of selected gas turbines using developed model 


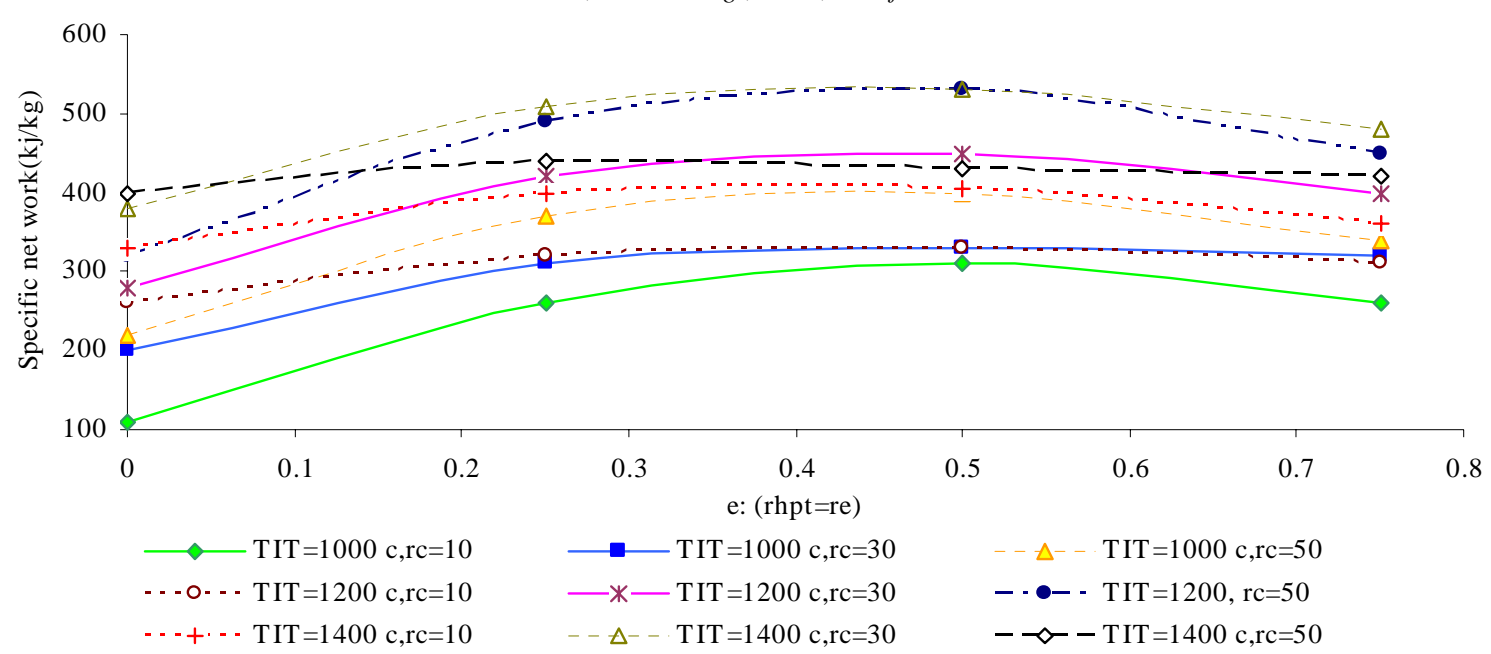

Fig. 5: Specific net work versus e for different TIT and pressure ratio values

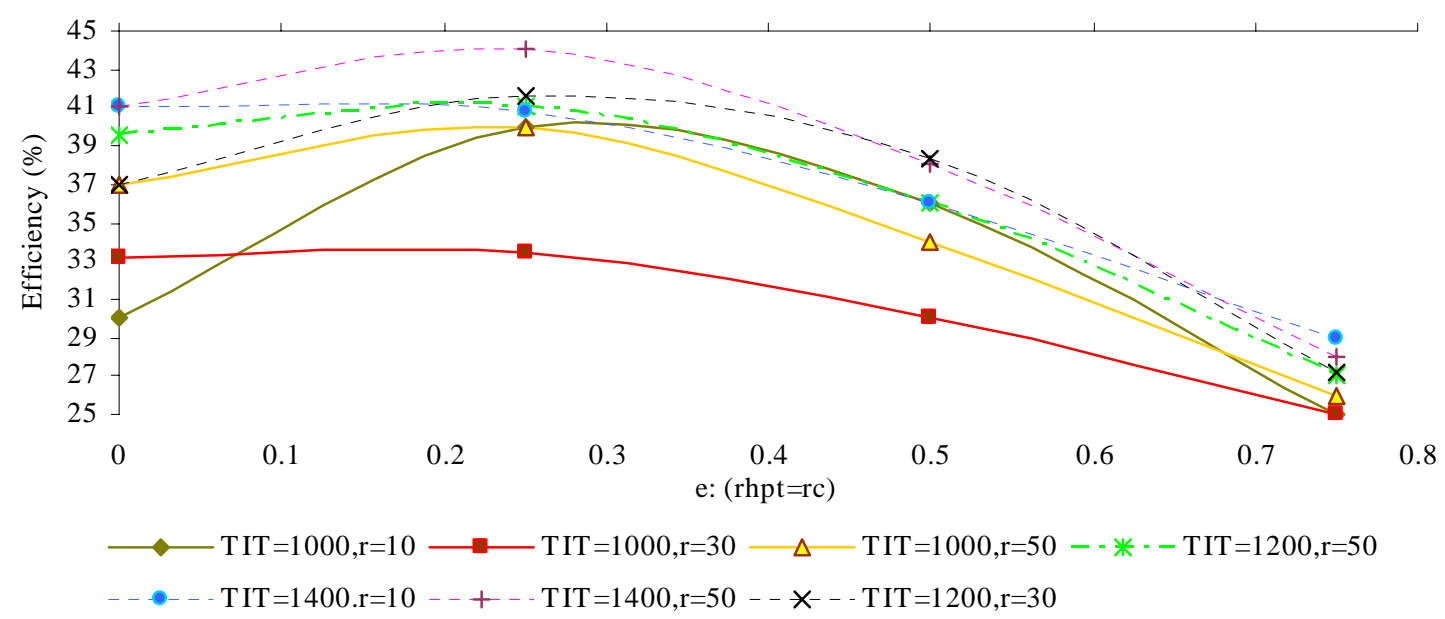

Fig. 6: Efficiency versus e for different TIT and pressure ratio values

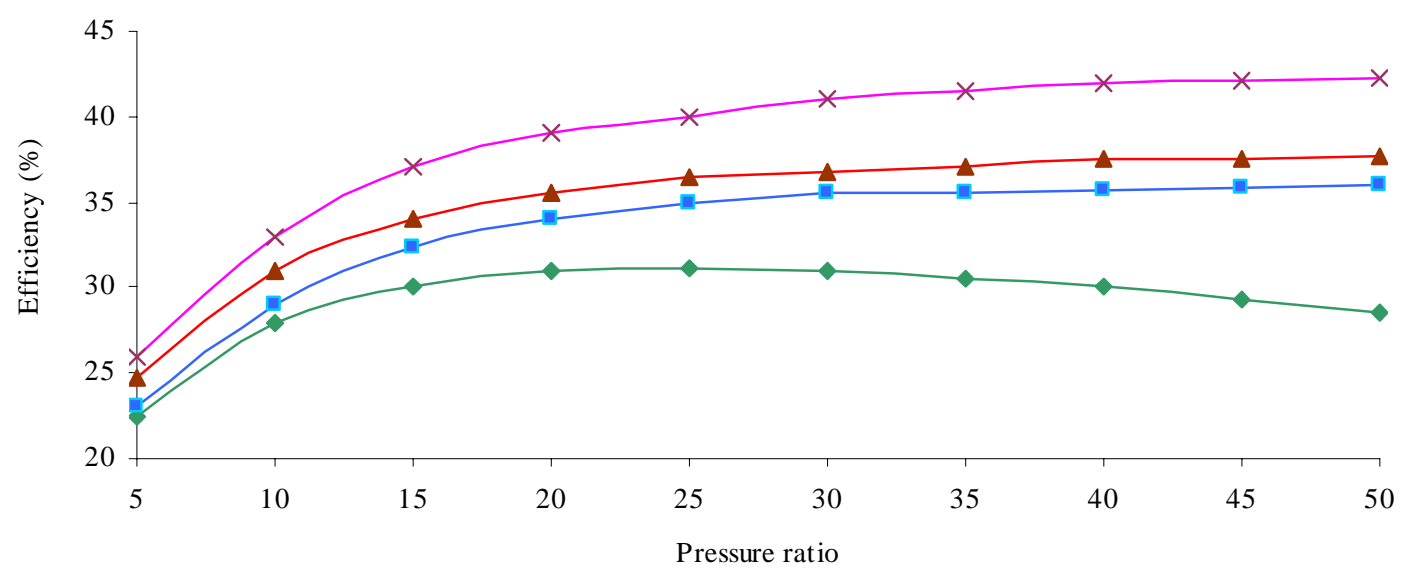

$\multimap$ RC (uncooled model) —- RC (cooled model1) $\multimap$ RC (cooled model2) $\leftarrow$ RC (cooled model3)

Fig. 7: Specific net work of the RC as predicted by various models 


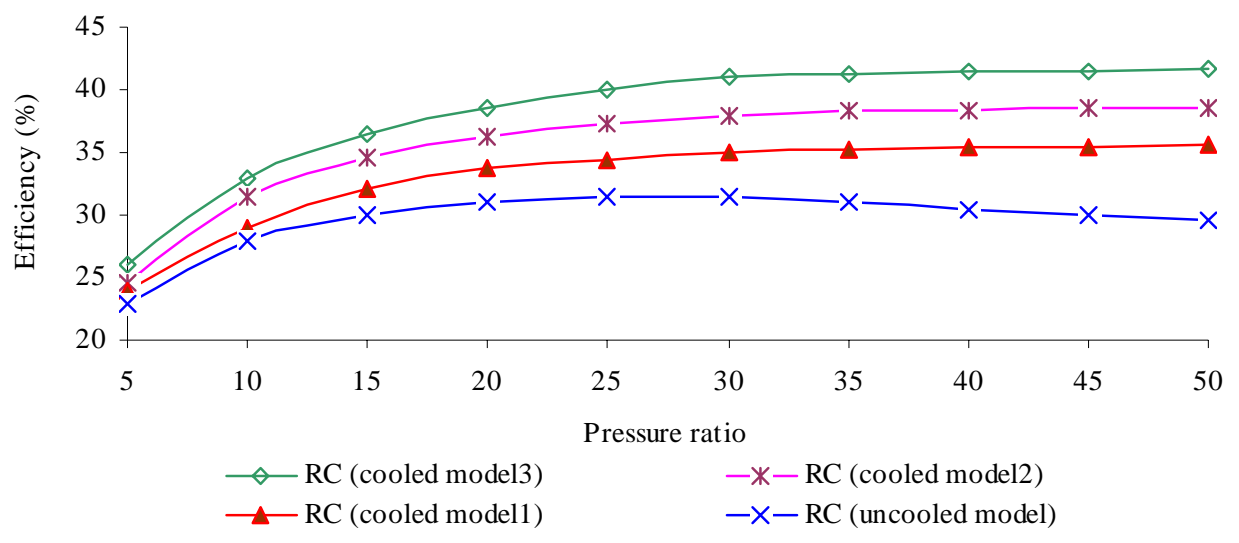

Fig. 8: Efficiency of the RC as predicted by various models

Design of the rc and rhc for maximum specific net work

It was previously shown that, for any given TIT and pressure ratio, the specific net work of the $\mathrm{RC}$ will be maximized for $\mathrm{e}=0.4-0.5$. This means that the pressure ratios and work outputs of both turbines should be equal. Figures 9 to 11 show efficiency versus specific net work for the SC, RC and RHC respectively for $\mathrm{e}=0.5$. The following results can be obtained. For the SC (Fig. 9), both specific net work and efficiency increase considerably as TIT rises. For any given TIT there is a peak value for specific net work. The maximum values of specific net work, depending on TIT, occur at pressure ratios of 10-20. For the RC (Fig. 10), the same behavior as that of the SC is observed, but the efficiency of the RC, for given conditions, is lower than that of the SC. However, its specific net work is higher. In this case, the maximum specific net work, depending on TIT, corresponds to $r=20-35$, which is higher than for the SC. Regarding the RHC (Fig. 11), it can be seen that the maximum specific net work occurs almost in the same range of pressure ratios as for the RC, and its value (for a given TIT and pressure ratio) is slightly lower than that of the RC because of the pressure drop in the recuperator. However, RHC efficiency, owing to the partial utilization of exhaust gas energy, is higher than that of both the SC and the RC. Some features of the above figures are shown in the first section of Table 2. Design of the RC for maximum specific net work (i.e. for TIT $=1200^{\circ} \mathrm{C}$ ) leads to an increment in specific net work of about $35 \%$ but to a reduction in efficiency of 5.6 per cent compared with the SC. On the other hand, design of the RHC for the same conditions increases the specific net work and efficiency respectively by 28 and $3 \%$. It should also be noted that the efficiency improvement of the RHC at lower TITs (i.e TIT $=1000$
${ }^{\circ} \mathrm{C}$ ) is much greater than at higher TITs. Hence, the costs related to the use of expensive super alloys to withstand high temperatures could be reduced. In summary it can be concluded that the design of the RC for maximum specific net work $(e=0.5)$ may increase its work output but reduces efficiency compared with the SC, and therefore this design philosophy is not so attractive in practice. One solution to overcome this drawback is to use a heat exchanger in the RC.

\section{Desgin of the rc and rhc for maximum efficiency}

It was previously shown that the efficiency of the $\mathrm{RC}$, for a given TIT and pressure ratio, will be maximized if $\mathrm{e}=0.2-0.3$ and therefore $\mathrm{r}_{\mathrm{hpt}}=\mathrm{r}_{\mathrm{lpt}}^{1 / 3}$. Figs. 12 and 13 show efficiency versus specific net work for the RC and $\mathrm{RHC}$ respectively for $\mathrm{e}=0.25$. The following results can be obtained. For the SC (Fig. 9) it is observed that, for any given TIT, there is a peak value for efficiency. The pressure ratios that correspond to peak values, depending on TIT, range from 25 to 40 . Figure 12 shows the behavior of the RC. It is observed that, similarly to the SC, there is also a peak efficiency for RC for any given TIT. The peak points occur at higher pressure ratios (40-50) than for the SC (25-40). The important result is that design of the $\mathrm{RC}$ for maximum efficiency yields higher efficiencies compared with the SC at the expense of sacrificing some specific net work increment. Figure 13 illustrates that the RHC improves efficiency compared with the SC and RC, particularly at lower TITs (i.e. TIT $=1000^{\circ} \mathrm{C}$ ). The second section of Table 2 demonstrates the results quantitatively. Based on this approach, the following conclusions can be drawn. If it is intended to obtain the highest efficiency and specific net work, the best solution is an RC designed 
Thermodynamic and environmental consideration of advanced gas...

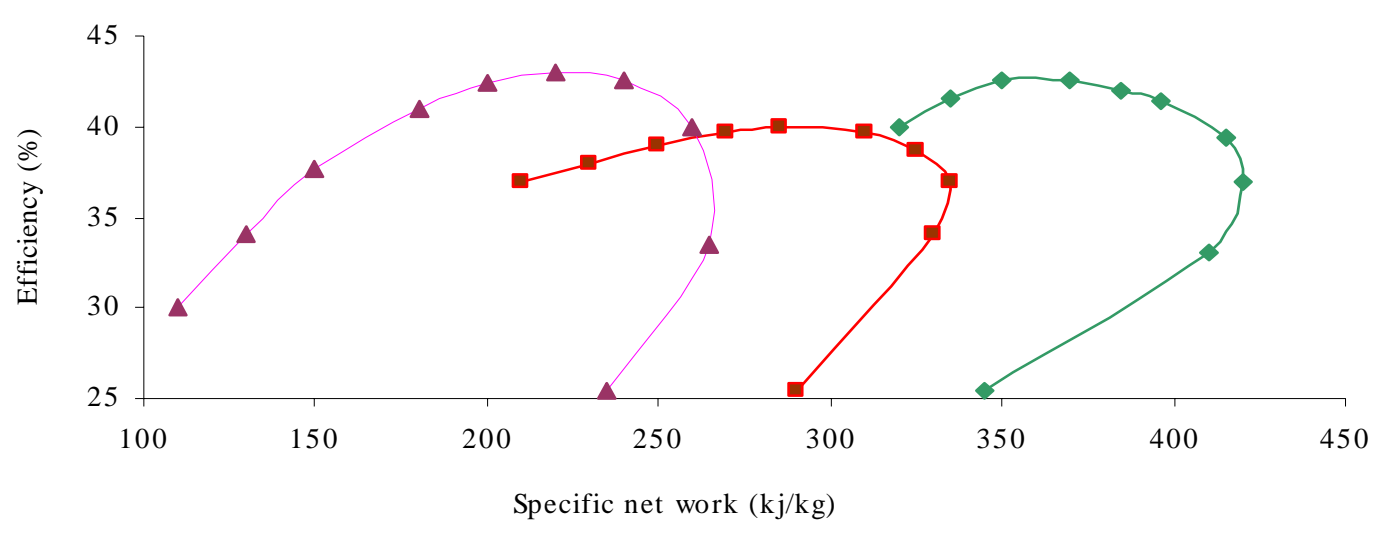

$\longrightarrow$ T IT $=1400 \mathrm{c} \longrightarrow$ T IT $=1200 \mathrm{c} \longrightarrow$ T IT $=1000 \mathrm{c}$

Fig. 9: Efficiency versus specific net work for the SC

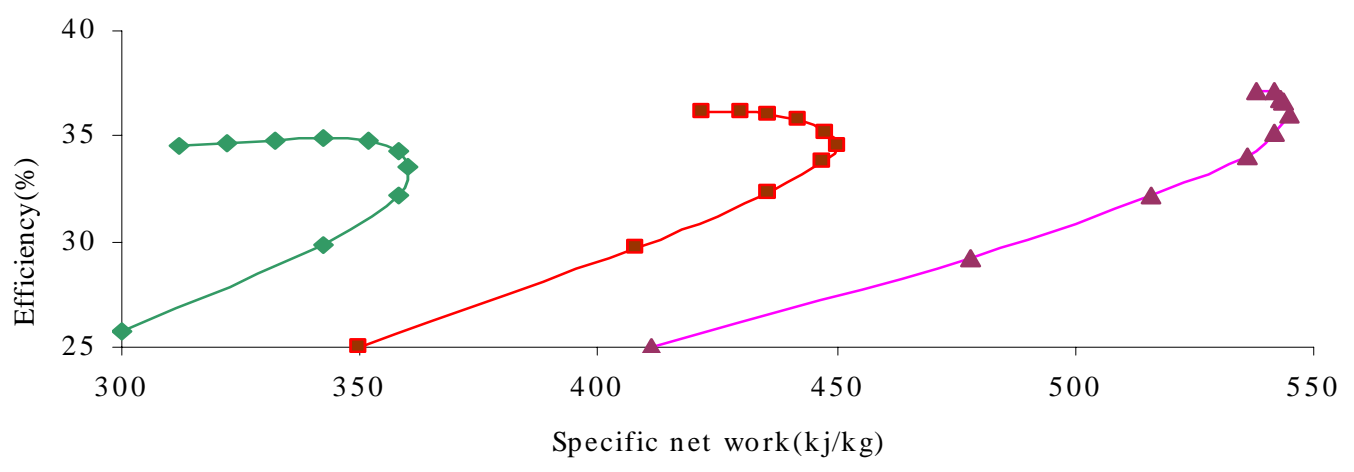

$\smile$ T IT $=1000 \mathrm{c} \longrightarrow \mathrm{T} \mathrm{IT}=1200 \mathrm{c} \longrightarrow \mathrm{T} \mathrm{IT}=1400 \mathrm{c}$

Fig. 10: Efficiency versus specific net work for the RC (e=0.5)

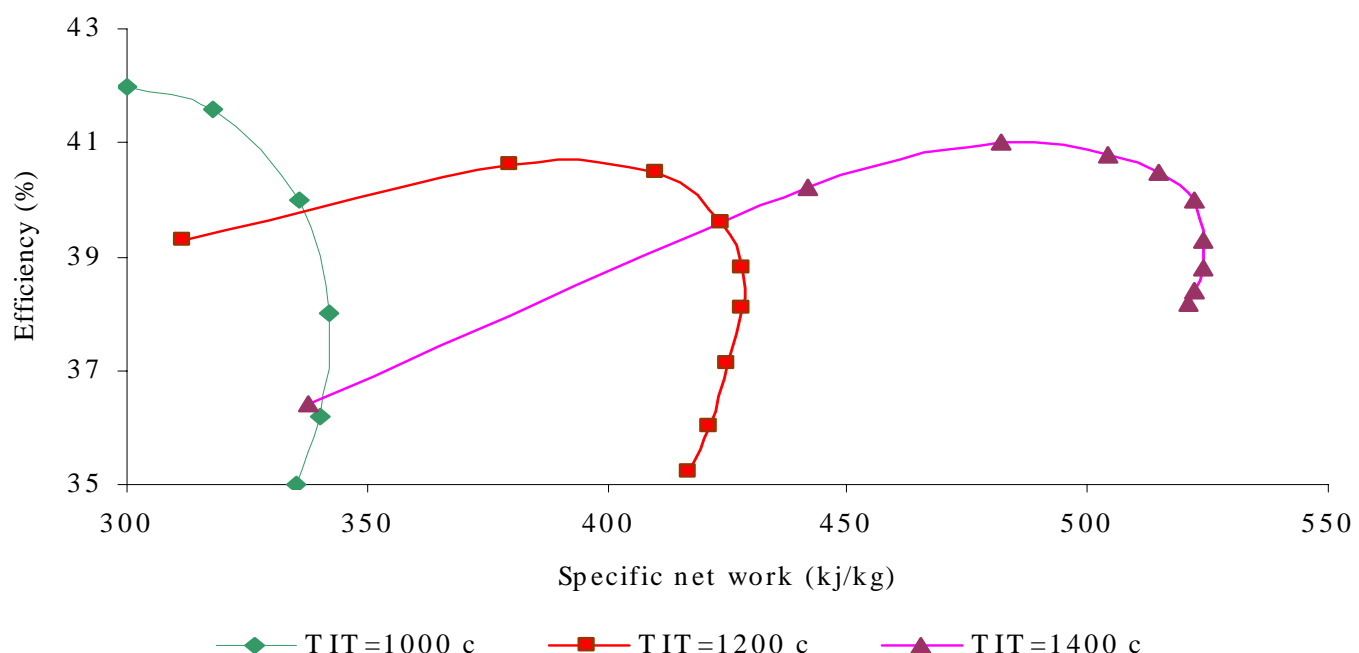

Fig. 11: Efficiency versus specific net work for the RHC $(\mathrm{e}=0.5)$ 


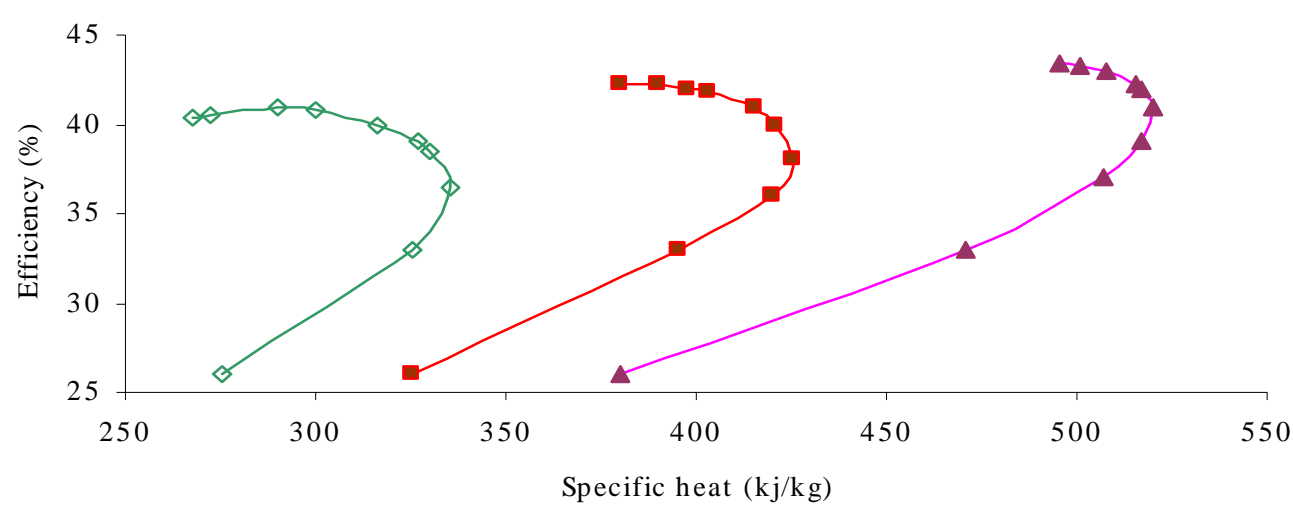

Fig. 12 Efficiency versus specific net work for the RC $(\mathrm{e}=0.25)$

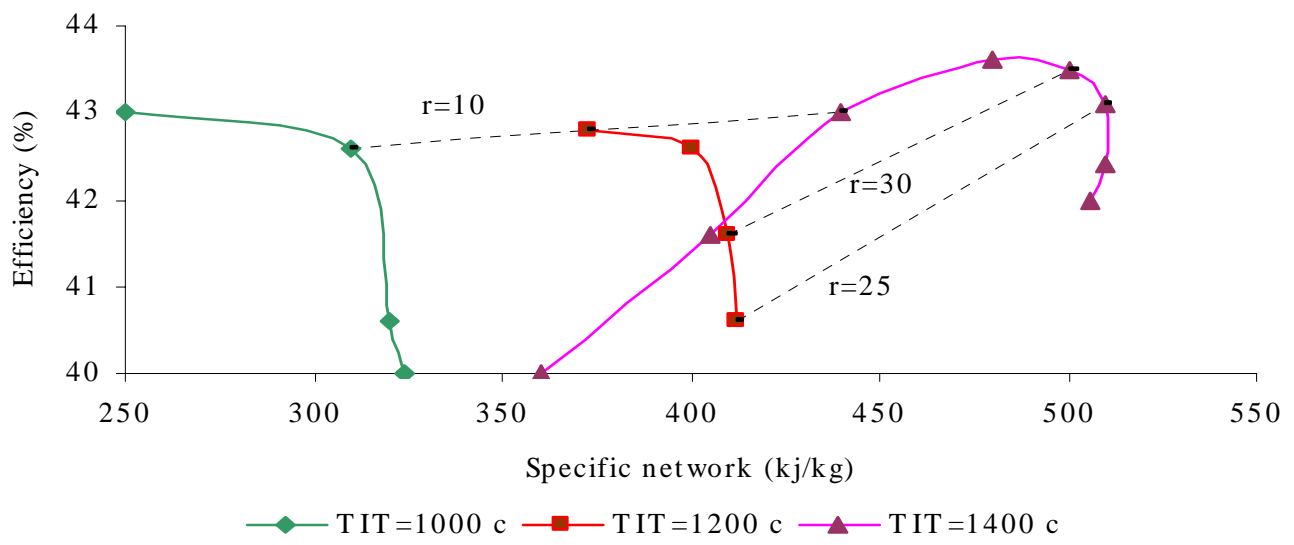

Fig. 13 Efficiency versus specific net work for the RHC $(e=0.25)$

for maximum efficiency at a higher TIT and pressure ratio (i.e. TIT $=1400^{\circ}$ Cand $r=50$ ). For these conditions an efficiency of $43.4 \%$ and a specific net work of 490 $\mathrm{kJ} / \mathrm{kg}$ can be obtained. For this case, the relevant stack temperature and cooling air fraction are respectively $5628 \mathrm{C}$ and 0.361 . On the other hand, if the priority is only the highest efficiency, then the attractive solution is an RHC designed for a lower TIT and pressure ratio (i.e. $\mathrm{TIT}=1000{ }^{\circ} \mathrm{C}$ and $\mathrm{r}=5$ ). In this case an efficiency of about $43 \%$ and a moderate value of specific net work (252 kJ/kg) may be achieved. The relevant LPT outlet temperature, stack temperature and cooling air fraction are 620 8C, $3168 \mathrm{C}$ and 0.096 respectively. It should be noted that the heat exchanger metal temperature is one of the constraints to be considered when trying to optimize the gas turbine heat exchanger cycle. The present limitation for this temperature is $600-650{ }^{\circ} \mathrm{C}$ which is almost satisfied by the optimum design conditions obtained for the RHC in this study. It is worth noting that all gas cycles usually have a pressure ratio for maximum efficiency and another for maximum specific work. A designer may not choose one or the other but a point between one and the other based on the duty and economic considerations. As measuring the NOx production by manufacturers, it has shown that 15-25 ppm less production in Nox emission was specified. So we will have $15-20 \%$ reduction in emission by using recuperator in ABB GT10 and GE9311FA models. Reduction in fuel consumption is the most important reason in this process.

\section{DISCUSSION AND CONCLUSION}

A detailed investigation has been made to predict the actual performance of a reheat gas turbine cycle and a cycle equipped with a reheat and a heat exchanger. A distinguishing feature of this study is to 
take into consideration the effect of almost all factors including cooling air on the performance criteria. In this model the cooling air required by the high-pressure and low-pressure turbines is extracted respectively from the outlet and intermediate stages of the compressor instead of being extracted totally from the compressor outlet. Of course, by this method the performance of the reheat can be improved considerably. The following important results were obtained from this research:

1. In actual reheat cycles, for any given pressure ratio and turbine inlet temperature, the maximum specific net work is achieved when the pressure ratios for the HPT and LPT are almost identical.

2. In reheat cycles, for any given pressure ratio and turbine inlet temperature, the maximum efficiency is achieved where $r_{h p t}=r_{l p t}^{1 / 3}$.

3. The design of the reheat cycles for maximum efficiency is more beneficial than their design for maximum specific net work.

4. Using a heat exchanger in the reheat cycle improves efficiency, especially at lower turbine inlet temperatures, e.g. $1000^{\circ} \mathrm{C}$.

5. By using heat exchanger, there were $15-20 \%$ reductions in NOx production.

\section{AKNOWLEDGMENT}

The authors would like to express their thanks for software support to K. Kheiri D., AAC R\&D Manager, who provided useful information during revised stage.

\section{REFERENCES}

Cohen, H., Rogers, G.F.C., Saravanamuttoo, H.L.N., (1996). Gas Turbine Theory, $4^{\text {th. }}$ Ed., Longman, London.

Consonni, S., (1998). Gas turbine cycles performance evaluation. In Proceedings of ASME Cogen Turbo Power Congress.
Crane, R.I.A., (1998). Critical analysis of the thermodynamic advantages of reheat in gas turbines. Proc. Instn Mech. Engrs, Part A: J. Power, Energy, 215, 81-87.

da Cunha, M.A., de Franca Mendes Carneiro, H.F., Travieso, L.E., Pilidis, P., Ramsden, K.W., (1998). An insight on intercooling and reheat gas turbine cycles. Proc. Instn Mech. Engrs, Part A: J. Power, Energy, 215(A2).

El-Masri, M.A., (1986). On thermodynamics of gas turbine cycles. Part 2: a model for expansion in cooled turbines. J. Eng. Gas Turb., Power, 108.

Erbes, M.R., Gay, R.R. and Cohn, A., Gate: a simulation code for analysis of gas-turbine power plants. ASME paper

Facchini, B., (1993). New prospects for use of regeneration in gas turbine cycles. ASME Cogen Turbo Conference, IGTI.

Katsavou, A., (1995). A review of the state-of the art gas turbine technology. M.Sc dissertation, UMIST, Manchester, UK.

Kreith, F., (1973). Principles of Heat Transfer, $3^{\text {rd. }}$ Ed., Intext Educational Publishers.

Ragland, T., (1995). A high efficiency recuperated cycle, optimized for reliable, low cost, industrial gas turbine engine. ASME paper 95-GT-321.

Sarabchi, K., (2000). A simple approach to gas turbines modeling. In Proceedings of Al Azhar Engineering $6^{\text {th. }}$ International Conference, Cairo, Egypt.

Sonntag, R.E., Borgnakke, C., VanWylen, G.J., (1998). Fundamentals of engineering thermodynamics, $5^{\text {th. }}$ Ed., John Wiley, New York.

Stecco, S.S., Facchini, B., (1989). A computer model for cooled expansion in gas turbine. In Proceedings of $3^{\text {rd. }}$ ASME Cogen Turbo Conference, France.

Stecco, S.S., Desideri, U., Bettagli, N., (1993). Humid air gas turbines cycle: a possible optimization. ASME paper 93GT-178.

GT PRO-GT MASTER, (2004). Thermoflow Inc., Sudbury, USA, Available from: www.thermoflow.com

Gas Turbine World 1995 Handbook, (1995). Pequot Publishing Inc., Fairfield, USA.

Cycle-Tempo, (2004). Cycle-Tempo Inc. Neatherland. Energy Analisys software.

De Paepe, M., Dick, E., (2000). Cycle improvements to steam injected gas turbines. Int. J. Energy Res., 24, 1081-1107.

\section{AUTHOR (S) BIOSKETCHES}

Sheikhbeigi, B., M.Sc. student in the Department of Energy, Graduate School of the Environment and Energy, Science and Research Campus, Islamic Azad University, Tehran, Iran.

Email: bsheikhbeigi@abanacds.com

Ghofrani, M.B., Ph.D. Professor in School of Mechanical Engineering, Sharif University of Technology, Tehran, Iran. Email: ghofrani@sharif.edu

This article should be referenced as follows:

Sheikhbeigi, B., Ghofrani, M.B., (2007). Thermodynamic and environmental consideration of advanced gas turbine cycles with reheat and recuperator. Int. J. Environ. Sci. Tech., 4 (2), 253-262. 